\title{
Correction to: Deterministic seismic risk assessment in the city of Aigion (W. Corinth Gulf, Greece) and juxtaposition with real damage due to the 1995 Mw6.4 earthquake
}

\author{
G. Giannaraki ${ }^{1} \cdot$ I. Kassaras $^{1}$ D $\cdot$ Z. Roumelioti ${ }^{2} \cdot$ D. Kazantzidou-Firtinidou ${ }^{1} \cdot$ A. Ganas $^{3}$ \\ Published online: 27 September 2018 \\ (c) Springer Nature B.V. 2018
}

\section{Correction to: Bulletin of Earthquake Engineering https://doi.org/10.1007/s10518-018-0464-z}

An incorrect version of Fig. 15 was erroneously published in the original article and needs to be correctly read as with this updated version (Fig. 15).

The original article can be found online at https://doi.org/10.1007/s10518-018-0464-z.

\section{Kassaras}

kassaras@geol.uoa.gr

1 Department of Geology and Geoenvironment, National and Kapodistrian University of Athens, 15784 Athens, Greece

2 Department of Civil Engineering, Aristotle University of Thessaloniki, 54124 Thessaloníki, Greece

3 Institute of Geodynamics, National Observatory of Athens, 11810 Athens, Greece 


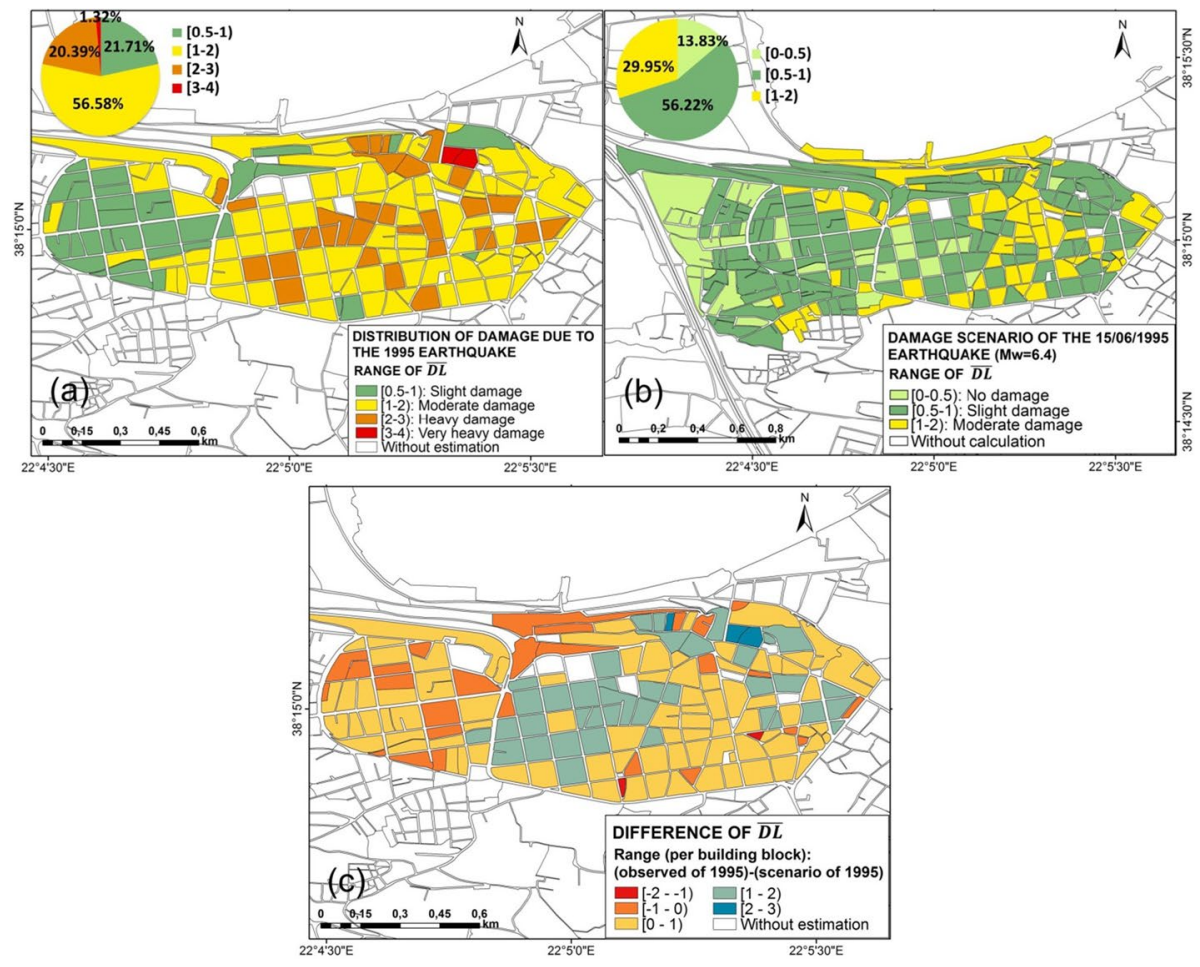

Fig. 15 Distribution of the average damage level $(\overline{D L})$ per building block in the city of Aigion, a due to the 1995 earthquake, and $\mathbf{b}$ regarding the respective simulated seismic scenario 1, in addition to $\mathbf{c}$ their comparative difference of $(\Delta \overline{D L})_{1995}$ in the common studied area. The embedded pie-charts present the corresponding percentages 